\title{
A Study on Perinatal Outcome in Women with Antepartum Hemorrhage
}

\author{
Dr.K.Murugalakshmi MD,DGO ${ }^{1,}$ Dr.V.Nandhini DGO,DNB(OG) ${ }^{2}$ \\ ${ }^{1}$ Associate Professor ${ }^{2}$ Assistant Professor Department Of Obstetrics \& Gynecology Coimbatore Medical \\ College Hospital,Coimbatore, Tamilnadu
}

\section{Introduction}

Antepartum hemorrhage (APH) is defined as the bleeding into or from the genital tract after the period of viability and before the period of delivery.It forms one of the main causes of maternal mortality and morbidity and perinatal mortality and morbidity. The

maternal mortality and morbidity are due to the disease perse but perinatal mortality and morbidity may be due to cause and as well as iatrogenic i.e.,the fetal life is terminated at extreme preterm inorder to decrease maternal morbidity and motality. This review article is done to study the perinatal outcome of these women who had suffered from APH.

\section{Aims And Objectives}

To study the perinatal outcome in those women affected by antepartum hemorrhage.

To study the causes and comorbid conditions associated with antepartum hemorrhage so as to treat the modifiable risk factors and to decrease adverse perinatal outcome.

\section{Materials And Methods}

Those women who presented with antepartum hemorrhage between the months of February 2016-July 2016 in Coimbatore Medical College Hospital,Coimbatore,Tamilnadu were taken up for study.

\section{Observation And Results}

\section{Incidence}

Of the total 3673 deliveries within the study period of 6 months 134 patients presented with history of third trimester bleeding but only 60 patients found to have antepartum hemorrhage(1.6\%).Of the 60 cases 46 $(77 \%)$ were abruptio placentae and placenta praevia $12(20 \%)$ and $2(3 \%)$ were bleeding due to unidentified cause.

Table 1

\begin{tabular}{|l|l|l|}
\hline Cause of APH & Frequency & Percentage \\
\hline Abruptio placenta & 46 & 77 \\
\hline Placenta praevia & 12 & 20 \\
\hline Unidentified & 2 & 3 \\
\hline Total & 60 & 100 \\
\hline
\end{tabular}

Age wise presentation of APH

Table 2

\begin{tabular}{|l|l|l|l|l|}
\hline Age & Total & Placenta praevia & Abruptio placentae & Unidentified \\
\hline$<20$ & 9 & 3 & 6 & 0 \\
\hline $21-30$ & 39 & 7 & 32 & 1 \\
\hline$>30$ & 10 & 2 & 8 & 1 \\
\hline
\end{tabular}

The above table tells 20-30 year age is most often affected by abruption.

\section{Associated comorbid conditions}

Table 3

\begin{tabular}{|l|l|l|l|l|}
\hline Comorbid conditions & Abruptio placenta & Percentage\% & Placenta praevia & Percentage\% \\
\hline PIH & 16 & 34 & - & - \\
\hline LSCS & 10 & 21 & 8 & 75 \\
\hline Chronic HT & 1 & 2 & - & - \\
\hline Twins & - & & 1 & \\
\hline & $27 / 46$ & $9 / 12$ & \\
\hline
\end{tabular}


Of the 46 cases 16 were associated with pregnancy induced hypertension (PIH),(16/46,34\%).21\% were associated with previous caesarean section, $75 \%$ of placenta praevia were associated with previous caesarean section.

If PIH is identified and treated 34\% of abruption could have been avoided, all these previous LSCS cases can be considered as High Risk and should be under strict vigilance to avoid the catastrophic accidents $(21 \%+75 \%)$ of both placenta praevia and abruption.

\section{Parity wise incidence}

\begin{tabular}{|l|l|l|l|}
\multicolumn{9}{|c|}{ Table 4 } \\
\hline APH & Primi & $>2<5$ & $>5$ \\
\hline Abruption & 16 & 27 & 3 \\
\hline Placenta previa & 3 & 8 & 1 \\
\hline Unidentified & - & 1 & 1 \\
\hline
\end{tabular}

Abruption and placenta praevia is more common in gravid $>2$ especially abruption which may be due to previous LSCS and abortion.

APH is associated with adverse perinatal outcome mainly due to

1. Hypoxia due to decreased blood flow

2. Extreme prematurity of life (earlier termination of pregnancy as a life saving measure).

3. Morbidity due to cerebral palsy following intracranial hemorrhage,birth asphyxia,fetal anaemia.

4. Lastly intra uterine fetal demise (IUFD), stillbirth.

Table 5

\begin{tabular}{|l|l|l|l|l|l|l|}
\hline Abruptio & & & Placenta previa & & Unidentified & \\
\hline Weight $(\mathrm{kg})$ & IUFD & LIVE BIRTH & IUFD & LIVE BIRTH & IUFD & $\begin{array}{l}\text { LIVE } \\
\text { BIRTH }\end{array}$ \\
\hline$<1$ & 5 & 1 & 1 & - & - & - \\
\hline $1-2$ & 16 & 5 & - & 3 & - & - \\
\hline$>2$ & 12 & 7 & 2 & 6 & - & 2 \\
\hline Total & 33 & 13 & 3 & 9 & 0 & 2 \\
\hline
\end{tabular}

Table 6

\begin{tabular}{|l|l|l|}
\hline Cause & Live birth & NICU death \\
\hline Abruption & 13 & 3 \\
\hline Placenta praevia & 9 & 1 \\
\hline
\end{tabular}

Of the alive babies of abruption and placenta praevia 13 and 9, 10 needed NICU admission and 4 were lost in the NICU due RDS (3),fetal anaemia(1).

\section{Discussion}

Above observations reveal that APH affects $1-2 \%$ of all pregnancies and abruption leads the way (77\%) followed by placenta praevia.APH is more common in the third decade, where second, fourth decades are equally affected. PIH (34\%), previous LSCS (96\%) are the high risk factors associated with APH where PIH is a modifiable risk factor and previous LSCS should be considered as high risk and followed up regularly.

APH is more common in multigravida where previous LSCS is the common cause, in primigravida this is mainly due to associated PIH.In primigrvida placenta praevia is also seen following ART procedures. Abruption causes IUFD due to late admissions presenting with $>50 \%$ of placenta being taken off and being taken up for termination ( $50 \%$ of the alive were terminated prematurely).

In placenta praevia IUFD is mainly due to central placenta praevia which need termination as a life saving measure. Of those babies admitted in NICU 3 died due to RDS (extreme prematurity) and one due to fetal anaemia.

\section{Conclusion}

Adverse fetal and perinatal outcome can be reduced by correcting the modifiable risk factors and identifying high risk cases at an early period using modern tools and keeping them under surveillance. 


\section{Bibliography}

[1]. International Journal of Scientific and Research Publications, Volume 4, Issue 2, February 20141 ISSN 2250-3153 www.ijsrp.org Study of Antepartum Haemorrhage \& Its Maternal \& Perinatal Outcome Dr. Archana Maurya, Dr. Sonal Arya Gajra Raja Medical College Gwalior

[2]. International Journal of Science and Research (IJSR) ISSN (Online): 2319-7064 Volume 3 Issue 1, January 2014 www.ijsr.net Maternal and Perinatal Outcome in Cases of Placenta Previa Anand D. Bhatt1, Aarti Meena2, Malini R. Desai3 1 3rd year post graduate student, B.J. Medical College, Civil Hospital, Ahmadabad, India 2 2nd year post graduate student, B.J. Medical College, Civil Hospital, Ahmadabad, India 3 Professor \& Head of Department, Obstetrics \& Gynecology, B.J. Medical College, civil hospital, Ahmadabad, India

[3]. International Journal of Scientific and Research Publications, Volume 5, Issue 2, February 20151 ISSN $2250-3153$ www.ijsrp.org Perinatal outcome in antepartum hemorrhage in teaching hospital of northern India- A prospective study Shaveta Jain* , Nitin Jain**, Pushpa Dahiya*, Seema Rohilla**, Roopa Malik**Department of obs\&Gynae Pt. B.D Sharma, PGIMS, Rohtak, Haryana, India **Department of Radiology Pt. B.D Sharma, PGIMS, Rohtak, Haryana, India

[4]. Khosla A, Dahiya V, Sangwan K, Rathor S. Perinatal outcome in antepartum haemorrhage. J Obstet Gyn India 1989; 9: $71-3$.

[5]. Brenner WF, Edelman DA, Hendricks CH. Characteristics of patients with placenta previa and results of expectant management. Am J Obstet Gynecol 1975; 155: 180-4.

[6]. Crane JMG, Van Denhof MC, Dodds L, Armson A, Listen R. Neonatal outcomes with placenta previa. Obstet Gynecol 1999; 93: 541-4. [15] Krohn M, Voigt L, McKnight B, Daling JR, Starzyk P, Benedetti TJ. Correlates of placenta abruption. Br J Obstet Gynecol 1987; 94: 333-40.

[7]. Arora R, Devi U, Majumdar K. Perinatal morbidity and mortality in antepartum haemorrhage. J Obstet Gynae India 2001; 51(3): 102-4.

[8]. http://data.worldbank.org/indicator/SH.DYN.NMRT

[9]. Hibbard BM, Jeffcoate TNA. Abruptio placentae. Obstet Gynecol 1966; 27: 155-67.

[10]. Chamberlain GVP, Philipp E, Howlett B, Masters K. Br Birth Obstet Gynecol 1970; 45: 160-3.

[11]. Green JR. Placenta abnormalities: Placenta previa and abruptio plcentae, Maternal fetal medicine. In: Creasy RK, Resnik R, editors. Principle and Practice. 3rd edtition. Philadelphia, WB Saunders, 1989; 588-602

[12]. Crane JMG, Van Denhof MC, Dodds L, Armson A, Listen R. Neonatal outcomes with placenta previa. Obstet Gynecol 1999; 93: 541-4.

[13]. Ambarisha Bhandiwad, Abhishek A. Bhandiwad. "A Study of Maternal and Fetal Outcome in Antepartum Haemorrhage". Journal of Evidence Based Medicine and Healthcare; Volume 1, Issue 6, August 2014; Page: 406-427.

[14]. Ananth CV, Berkowitz GS, Savitz DA, Lapinski RH. Placental abruption and adverse perinatal outcomes. JAMA 1999; 282: 16461651 .

[15]. Myerscough P R, Antepartum haemorrhage: Placenta Praevia, chapter 29, operative obstetrics, 10th Edition, Bailliere Tindall, 2004; $400-414$. 